\title{
Violências e acidentes nos idosos assistidos no atendimento pré-hospitalar no Espírito Santo, Brasil
}

Violence and accidents in the elderly assisted in the Pre-Hospital Care in Espirito Santo, Brazil

\author{
LEONARDO FRANÇA VIEIRA @ \\ CAIO DUARTE NETO . $^{1}$ \\ LUCIANA CARRUPT MACHADO SOGAME (‥1 \\ ${ }^{1}$ Escola Superior de Ciências da Santa Casa de Misericórdia de Vitória, Vitória, ES, Brasil.
}

RESUMO - A transição demográfica tem representado um processo de modificação das relações sociais no Brasil. Associado a isso, as violências e os acidentes se mantêm em um movimento de ascensão epidemiológica por décadas e vêm impondo maior impacto sobre a população idosa. Propõe-se uma reflexão acerca da violência e acidentes contra os idosos. Realizou-se uma análise da base de dados do Sistema de Informação sobre Mortalidade do SUS e um estudo transversal das ocorrências de acidentes e violências realizadas pelo Serviço de Atendimento Móvel de Urgência do Espírito Santo (SAMU-ES) de 2015. Concluiu-se que os óbitos no Brasil em idosos por acidentes e violências aumentou nos últimos 10 anos e que $6 \%$ dos pacientes assistidos pelo SAMU-ES são idosos vitimados por essas ocorrências. As quedas são as principais causas de agravos e sugere-se que parte dos seus registros se referem à violência doméstica ocultada.

Palavras-chave: Violência. Acidentes. Idosos. Atendimento pré-Hospitalar.

ABSTRACT - The demographic transition has been a process of modification of social relations in Brazil. Associated to this, the violence and accidents have been in a movement of epidemiological rise for decades and have imposed a greater impact on the elderly population. It is proposed to reflect on violence and accidents against the elderly. An analysis of the SUS Mortality Information System database and a cross-sectional study of the occurrences of accidents and violence carried out by the Mobile Urgent Care Service of Espírito Santo (SAMU-ES) in 2015. It was concluded that deaths in Brazil in the elderly due to accidents and violence increased in the last 10 years and that $6 \%$ of patients assisted by SAMU-ES are elderly victims of these events. Falls are the main causes of illness and it is suggested that some of their records refer to hidden domestic violence.

Keywords: Violence. Accidents. Aged. Emergency Medical Services. 


\section{Introdução}

D esde os tempos mais remotos, a violência é um fenômeno que está presente nas relações interpessoais da humanidade e perdura na evolução da história humana através de mutações intrínsecas em cada contexto histórico como forma de impor o poder, nas disputas das estruturas sociais e em algumas situações na luta pela sobrevivência (GENTILLI, 2015).

No Brasil, identificamos que a sua evolução histórica transpõe diversas formas de hostilidades exercidas por aqueles que detinham o poder contra os grupos menos favorecidos, como o índio, o negro, o operário, o homossexual, a criança, a mulher e a pessoa idosa (SOARES, 2015; GARCIA FILHO; SAMPAIO, 2014).

Desde o início da década de 1980 até meados da década de 2000, as violências e os acidentes constituíram a segunda principal causa de morte da população geral no Brasil, com uma maior frequência observada nas pessoas com idade entre 5 e 39 anos, nos quais esses eventos representam a principal causa de óbitos (MINAYO, 2007).

O evento de maus-tratos contra o idoso não é um episódio recente na história, mas foi somente a partir de 1975 que a abordagem do assunto foi inserida nos debates da sociedade científica em um contexto mundial, através da publicação de um periódico inglês que caracterizou o termo "espancamento de avós" (ALBUQUERQUE, 2010).

A causa mais comum de agravo à saúde da população idosa relacionada aos acidentes e às violências é a queda da própria altura, seguida dos eventos traumáticos devido a atropelamento e acidentes automobilísticos, seguidamente dos eventos motivados por violência, como a agressão física e ferimento por arma branca (BARROS et al., 2013).

Segundo o Plano de Ação para o Enfrentamento da Violência Contra a Pessoa Idosa, ao analisar o Sistema de Informações Hospitalares do Sistema Único de Saúde (SIHSUS) no ano de 2004, o custo médio pago pelo SUS pelas internações hospitalares de idosos por causas relacionadas a acidentes e violências foi de $\mathrm{R} \$ 1.069,80$ por pessoa, enquanto na população geral o custo correspondeu a $\mathrm{R} \$ 714,71$. A mortalidade dos idosos também foi maior: 5,42\%/100.000, comparada a 2,69\%/100.000 da população em geral (BRASIL, 2005).

Destaca-se que em pesquisa realizado por Silveira et al. (2013) ao analisar os dados do Departamento de Informática do Sistema Único de Saúde (DATASUS), sobre as internações hospitalares de idosos no Brasil no período de 2002 a 2011, verificou-se que os idosos representavam 16,11\% da população geral no período de estudo, mas contribuíram para $27,85 \%$ das internações e $36,47 \%$ dos recursos pagos. Entretanto Reis et al. (2016) afirmam que o aumento dos gastos com a saúde de idosos se deve à interação de fatores como mudanças tecnológicas, nível de renda e proximidade à morte, que se relacionam ao processo do envelhecimento.

No ano de 2014, no estado do Espírito Santo, os acidentes e violências foram responsáveis por 5,87\% dos casos de morte na população idosa, ficando em quinto lugar dentre as principais causas (ESPÍRITO SANTO, 2014).

Diante disso, pretende-se com este artigo desenvolver uma reflexão acerca das violências e acidentes nos idosos atendidos pelo Serviço de Atendimento Móvel de Urgência (Samu) do Espírito Santo. Para tanto, em um primeiro momento, foi realizado um levantamento sobre a realidade da mortalidade por acidentes e violências no âmbito nacional, por meio da análise da base de dados do Sistema de Informação sobre Mortalidade (SIM) do DATASUS, através de um estudo ecológico de série temporal entre os anos de 1979 e 2015.

Além disso, para estudar a realidade do idoso do Espírito Santo vitimado por violências e acidentes, trazem-se neste estudo, dados de uma pesquisa de campo realizada no SAMU 192 do estado, onde foram registradas as informações de uma amostra dos atendimentos realizados no primeiro semestre do ano de 2015 


\section{O flagelo das violências e acidentes na população idosa do Brasil}

A violência e o acidente representam um grande problema social para a população brasileira. $O$ aumento da ocorrência desses agravos no Brasil foi impulsionado a partir da década de 1980. Dentre diversos fatores, destacamos a migração em massa da população rural para as regiões urbanas do País que ocorreu nesse período, onde as pessoas buscavam melhores oportunidades e condições de vida diante do processo de intensificação da industrialização (SMARZARO, 2005).

Como consequência, grande parte dessa massa que chegou às metrópoles instituiu suas residências de maneira improvisada, desordenada e sem condições básicas para sobrevivência. A falta de recursos e o insucesso na busca de um meio digno para garantir o sustento da família, levou parte dessas pessoas a começar a praticar atos ilícitos como meio de sobrevivência (SMARZARO, 2005).

Em meio ao caos instaurado nas regiões periféricas das grandes cidades, outro meio de violência foi estabelecido, desta vez através das organizações criminosas com a exploração do narcotráfico, que levou muitos jovens ao crime (MINAYO; SOUZA, 1999).

A partir do final da década de 1970, os acidentes e as violências trilharam uma escalada nas estatísticas de morbimortalidade, chegando a representar a segunda principal causa de morte no País durante as décadas de 1980 e 1990, precedida apenas pelas doenças do aparelho circulatório, como podemos identificar no Gráfico 1 (BRASIL, 2018a).

Gráfico 1 - Série Histórica das principais causas de óbitos no Brasil entre os anos de 1979 e 2015, segundo capítulos da Classificação Internacional das Doenças (CID)

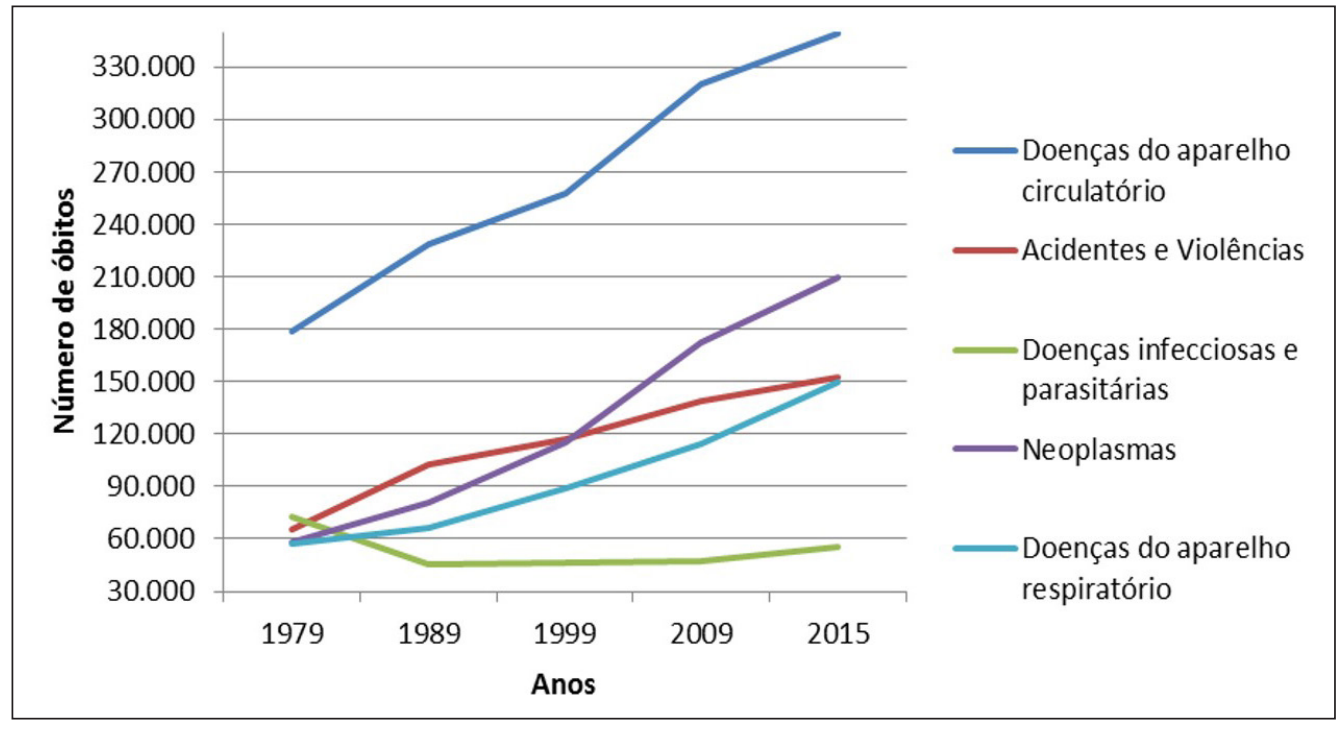

Fonte: Dados tratados pelo autor e elaborados a partir de informações coletadas no DATASUS/SIM [2018].

Entre os anos de 1980 e 2004, ocorreu uma projeção do coeficiente de mortalidade por agressão de 14,1 para 27,2 por 100 mil habitantes, o que significa um crescimento de $92,3 \%$ para o risco de morte, ou seja, quase que dobrou em apenas 24 anos (GARCIA FILHO; SAMPAIO, 2014).

Analisado o Gráfico 1, podemos identificar que a partir do ano de 2000 os acidentes e as violências passaram a ocupar o terceiro lugar dentre as principais causas de óbito no Brasil, sendo precedidos pelos problemas relacionados ao aparelho cardiovascular e neoplasias. Entretanto, ainda configuram um problema social de grande relevância para a população brasileira (BRASIL, 2018a; 2018b).

As violências e os acidentes podem ocorrer em qualquer momento da vida, mas ao analisarmos o Gráfico 2, verificamos que o pico das ocorrências transcorre principalmente sobre os indivíduos com idades 
entre 20 e 29 anos, entretanto, nos anos de 2009 e 2015 um novo pico é observado nas pessoas com 80 anos ou mais.

Gráfico 2 - Distribuição dos óbitos por acidentes e violências no Brasil, segundo ciclo de vida, entre os anos de 1979 e 2015, segundo capítulos da Classificação Internacional das Doenças (CID)

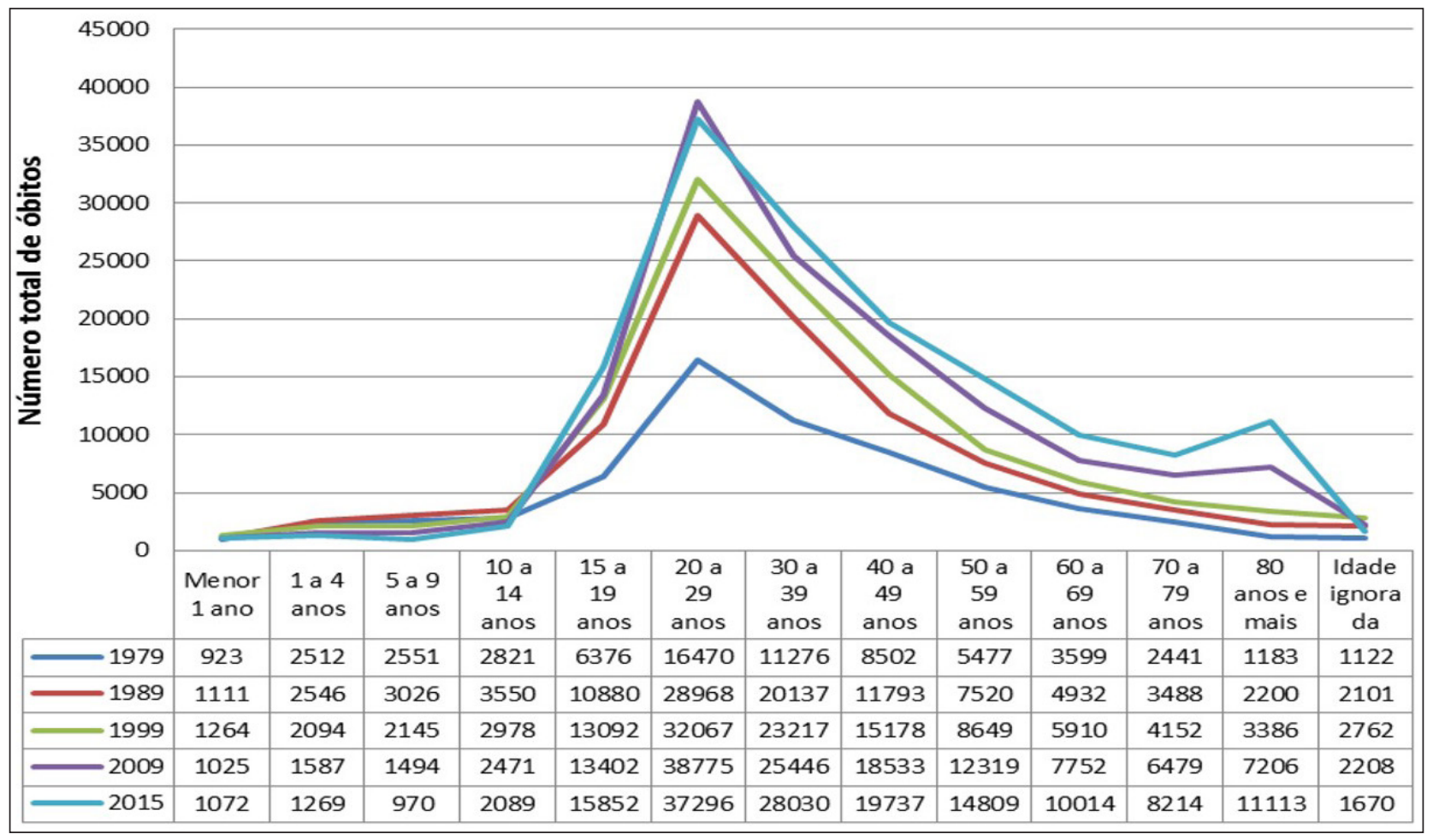

Fonte: Dados tratados pelo autor e elaborados a partir de informações coletadas no DATASUS/SIM [2018].

Em consonância com estes dados, um estudo realizado na cidade de São Paulo, em que um dos objetivos foi comparar o equilíbrio e a dependência funcional de idosos por idade, concluiu que idosos mais velhos, ou seja, com 80 anos ou mais, apresentam mais risco de sofrer queda em consequência da alteração do equilíbrio e da marcha (NAKAGAWA et al., 2017; BARROS et al., 2013).

Uma hipótese que podemos considerar para o aumento da morbidade e mortalidade em decorrência das violências e acidentes é o fenômeno que vem ocorrendo no cenário mundial, denominado transição demográfica. Esse fenômeno é caracterizado pela diminuição da natalidade associado a uma maior expectativa de vida, culminando no aumento proporcional da população idosa (INSTITUTO BRASILEIRO DE GEOGRAFIA E ESTATÍSTICA, 2016).

No Brasil, esse evento não é diferente, no ano de 2004 a participação da população com 60 anos ou mais era de 9,6\% do total de habitantes, enquanto que em 2015 essa proporção foi de 14,3\%, ou seja, um crescimento de 4,7\% em um período de 11 anos (INSTITUTO BRASILEIRO DE GEOGRAFIA E ESTATÍSTICA, 2016).

Nesse contexto, a violência e os acidentes contra a pessoa idosa em especial, se transformaram em um problema social de grande relevância. Em consequência das alterações fisiológicas que ocorrem com o avançar da idade, tais quais: a acuidade visual reduzida, a mobilidade prejudicada, os problemas relacionados à audição; esse grupo torna-se ainda mais vulnerável a esses eventos (SOUZA et al., 2003; VERAS, 2009). 
Essa vulnerabilidade dos idosos aos acidentes e às violências é potencializada pelo estigma social, que por diversos contextos e tempos históricos está associada à rejeição da figura do velho, por ser considerado um estereótipo debilitado e improdutivo, diante de uma sociedade capitalista onde o indivíduo vale aquilo que ele produz (TEIXEIRA et al., 2016).

Como podemos identificar no Gráfico 3, somente no ano de 2015, foram registradas 10.125 mortes de idosos cuja causa determinada ficou a cargo dos eventos relacionados à queda acidental e outros 6.218 óbitos por acidentes de transporte, seguidos dos homicídios que representaram 2.428 mortes (BRASIL, 2018a; 2018b).

Gráfico 3 - Distribuição dos óbitos por acidentes e violências na população idosa no Brasil, durante os anos de 1979 a 2015, segundo grupos do capítulo sobre causas externas da Classificação Internacional das Doenças

\begin{tabular}{|c|c|c|c|c|c|c|}
\hline \multirow{6}{*}{ 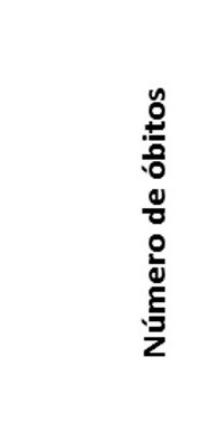 } & \multirow{2}{*}{$\begin{array}{l}12.000 \\
10.000\end{array}$} & & & & & \\
\hline & & & & & & \\
\hline & 6.000 & & & & & \\
\hline & 4.000 & & & & & \\
\hline & 2.000 & \multicolumn{3}{|c|}{ 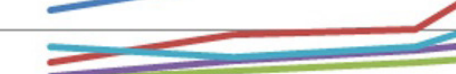 } & & \\
\hline & 0 & 1979 & 1989 & 1999 & 2009 & 2015 \\
\hline Acidente & transporte & 2.715 & 3665 & 3797 & 5.417 & 6.218 \\
\hline Quedas & ntais & 969 & 1878 & 2040 & 5671 & 10125 \\
\hline —Suicídios & & 392 & 676 & 924 & 1378 & 1943 \\
\hline —Homicídi & & 470 & 992 & 1377 & 1925 & 2428 \\
\hline $\begin{array}{r}\text { Eventos } \\
\text { inde }\end{array}$ & $\begin{array}{l}\text { intesão é } \\
\text { inada }\end{array}$ & 1458 & 1148 & 1473 & 3364 & 3099 \\
\hline
\end{tabular}

Fonte: Dados tratados pelo autor e elaborados a partir das informações coletadas no DATASUS/SIM [2018].

Esses dados demonstram uma parte do problema social que os acidentes e as violências sobre os idosos representam para a população brasileira, especialmente se for considerada a maior fragilidade que esse grupo demonstra diante de uma lesão, além de um menor potencial de recuperação e um maior tempo de internação quando comparada aos grupos etários mais jovens nos casos não fatais (SOUZA et al., 2003).

Potencializando essa questão, os acidentes que ocorrem essencialmente no âmbito doméstico requerem um olhar especial, pois podem camuflar episódios de violência (GROSSI et al., 2007). Além disso, a maior fração dos casos de violência fica no anonimato, pois os registros desses eventos acontecem principalmente quando decorrem de atendimentos em serviços de saúde ou em óbito. Deste modo, diversas outras formas de violência presentes no cotidiano da sociedade não recebem a devida atenção (GENTILLI, 2015).

É na família onde se encontra o autor das agressões na maior parte dos casos de violência contra a pessoa idosa. Portanto, a instituição de políticas públicas e de redes de proteção podem ser interessantes, mas não são suficientes para erradicar esses eventos. É necessário conhecer as características de vida dessas vítimas para a adoção de estratégias mais eficazes no enfrentamento desse fenômeno ascendente na sociedade contemporânea (DIEL; BARBIANI, 2018). 
Como medida de intervenção foram instituídas políticas públicas voltadas para o tema, dentre elas a Política Nacional do Idoso (1996), o Estatuto do Idoso (2003) e a Política Nacional de Saúde da Pessoa Idosa (2006). Entretanto, autores como Paiva (2014) e Bernado (2014) afirmam que a implementação dessas políticas é lenta, tem ficado aquém do modelo preconizado e não tem dado respostas às questões impostas pela transição demográfica em curso no País. As autoras também discutem que essa implantação é prejudicada pela hegemonia do pensamento neoliberal, que se intensificou nos anos 1990 e trouxe como consequência retrocesso nas áreas sociais e descompasso entre as formulações legais e a realidade.

No Estado do Espírito Santo em 2008 foi estabelecido o Programa de Atenção ao Idoso que teve como objetivo elaborar estratégias para os municípios implantarem o Programa Municipal de Atenção à Saúde da Pessoa Idoso (Promaspi). Visando estabelecer diretrizes, normas e estratégias para a organização da rede de atenção à saúde da pessoa idosa, bem como instituir a Equipe Técnica de Referência de Atenção à Saúde da Pessoa Idosa da Secretaria de Estado da Saúde do Espírito Santo - SESA, foi lançada, em 2012, a Política Estadual de Atenção à Saúde da Pessoa Idosa (ESPÍRITO SANTO, 2012).

No ano de 2018 a SESA iniciou a discussão sobre a reorganização da rede de atenção à saúde do idoso no Espírito Santo. Nesse evento foi destacada a importância do reconhecimento do idoso para a elaboração de uma rede de atenção adequada, sendo levantados diversos temas estratégicos voltados para a prevenção e a proteção dessa população, tais quais: saúde e envelhecimento, estratificação do idoso, reconhecimento rápido do idoso frágil, e elaboração e implementação do plano de cuidados personalizado (ESPÍRITO SANTO, 2018).

Além dessas políticas, que são específicas para a população idosa, tem-se a Política Nacional de Redução da Morbimortalidade por Acidentes e Violências, implantada por meio da Portaria no 737, de 16 de maio de 2001, que representa um instrumento de orientação da atuação do setor da saúde, mediante o desenvolvimento de um conjunto de ações articuladas e sistematizadas. Segundo Minayo et al. (2018), como ações relativas às diretrizes dessa Política, foram instituídos, em 2004, a Rede Nacional de Prevenção da Violência e Promoção da Saúde e os Núcleos de Prevenção de Violências e Promoção da Saúde; em 2006, a Rede de Serviços Sentinela de Violências e Acidentes; em 2011, o sistema de Vigilância de Violências e Acidentes - VIVA e a sistematização, ampliação e consolidação do atendimento pré-hospitalar.

Diante do exposto, pode-se afirmar que existiram vários avanços após a homologação Política Nacional de Redução da Morbimortalidade por Acidentes e Violências, mas muitos desafios ainda persistem. Para Minayo et al. (2018 p. 2014) "a violência, em suas distintas formas de expressão necessita tornar-se parte da agenda prioritária do setor saúde, conforme ainda demonstram sua magnitude e impactos na qualidade de vida da população".

Um fator de grande relevância para a sobrevida da vítima de acidentes e violências é o atendimento precoce. Diante das especificidades da população idosa, essa necessidade torna-se ainda maior. Deste modo, a instituição de medidas de promoção e prevenção desses eventos, assim como a implantação e organização de um sistema de resposta diante desses casos é extremamente imprescindível (HEYDARI-KHAYAT et al., 2014). Neste contexto Minayo et al. (2018) apontam que o atendimento pré-hospitalar é uma dimensão fundamental para a diminuição do tempo de internação, das sequelas e das mortes.

Deste modo, a articulação entre os serviços de atendimento pré-hospitalar móvel, por meio de suas centrais de regulação médica, e as instituições hospitalares, favorece uma assistência apropriada às vítimas de acidentes e de violências (MINAYO, 2009).

\section{0 retrato dos acidentes e violências nos idosos assistidos pelo SAMU 192 no Espírito Santo}

No ano de 2015, o SAMU 192 da Região Metropolitana do Estado do Espírito Santo, compreendia na sua área de abrangência um total de 17 municípios, que totalizavam 2.155.348 residentes (BRASIL, 2018c).

No primeiro semestre desse mesmo ano foram realizados pelo SAMU 192 da Região Metropolitana do Espírito Santo 25.410 atendimentos, segundo os dados cedidos pelo Serviço. Para a realização do presente 
estudo, procedeu-se um cálculo estatístico para estimar a quantidade de participantes necessários para o desenvolvimento da pesquisa, onde se obteve o total de 984 atendimentos.

Deste modo, a seleção dos idosos ocorreu por meio de processo de amostragem aleatória sistematizada para formação do banco de dados do estudo denominado "Rede de Urgência e Emergência: Estudo do SAMU 192 na Região Metropolitana do Espírito Santo". Em seguida, foi realizada uma análise secundária para a realização do presente estudo, onde foram incluídos os pacientes com idade de 60 anos ou mais, de ambos os sexos, atendidos em decorrência de acidentes e violências. Foram excluídos do estudo os pacientes cujas informações disponibilizadas estavam incompletas. $O$ estudo foi submetido ao Comitê de Ética em Pesquisa e obteve a aprovação através do parecer no 1.748.503.

Os dados foram obtidos por meio de uma ficha de coleta de dados elaborada pelos pesquisadores. As variáveis selecionadas para este estudo foram: idade, sexo (masculino; feminino), tipo de acidentes e violências (quedas; acidente de trânsito; agressão), turno da solicitação (manhã; tarde; noite), recurso enviado (Unidade de Suporte Básico - USB; Unidade de Suporte Avançado - USA), hálito etílico e o desfecho do atendimento (encaminhamento para instituição de saúde; recusa de transporte; liberado no local; óbito no local).

Dentre os recursos disponíveis para a assistência às vítimas, o SAMU-ES tem a USB, tripulada por dois profissionais, categorizados em técnico em enfermagem e motorista socorrista; a USA composta por três profissionais, a saber: um médico, um enfermeiro e um motorista socorrista; a Motolância, cujo deslocamento era realizado por meio de duas motocicletas conduzidas por um enfermeiro e um técnico em enfermagem; e a equipe de Suporte Aeromédico, que tripula um helicóptero quando julgado necessário pela regulação médica, sendo composta por um médico e um enfermeiro.

Do total da amostra (984 participantes), referente aos atendimentos realizados à população geral durante o primeiro semestre do ano de 2015, identificamos que 339 (34\%) indivíduos eram idosos, ou seja, pessoas com idade igual ou maior que 60 anos. Não obstante, do total da amostra foram selecionados 68 atendimentos (7\% dos casos) por se tratarem de vítimas de violências e acidentes. Mas, como seis participantes apresentaram dados incompletos, a amostra foi composta por 62 (6\%) idosos.

Em uma comparação com outras regiões, o total de 34\%, referente aos idosos atendidos pelo SAMU-ES, ficou muito além dos $23 \%$ identificados por Mello e Moysés (2010), nos Centros Municipais de Urgências Médicas do município de Curitiba - PR. Também foi maior o percentual de atendimentos préhospitalares aos idosos vitimados por acidentes e violências quando comparados aos dados dos serviços pré-hospitalares móveis desse mesmo município, pois, enquanto na Região Metropolitana do Espírito Santo $6 \%$ dos atendimentos foram direcionados a idosos vitimados por acidentes e violências no ano de 2015, em Curitiba esse percentual foi de $4 \%$ (MELLO; MOYSÉS, 2010).-

Os idosos vitimados por violências e acidentes atendidos pelo SAMU 192 apresentaram um intervalo de idade entre 60 e 98 anos, com uma média de idade de 73 anos; $65 \%$ desses casos ocorreram em idosos com idade entre 60 e 79 anos. Contrastando com a realidade encontrada por Cavalcante et al. (2012), que ao realizarem um estudo sobre os fatores associados às quedas nos idosos de uma comunidade, onde identificaram que dos idosos que relataram ter sofrido pelo menos uma queda nos últimos 24 meses, 57\% tinha idade entre 80 e 89 anos. É verdade que as populações incluídas nos dois estudos apresentam certa variação do tipo de evento ao qual o idoso foi exposto, considerando que no estudo de Cavalcante et al. (2012) foram incluídos apenas os idosos vitimados por queda e no presente estudo foram considerados todos os tipos de acidentes e violências. Entretanto, vale fazer uma alusão, considerando que $81 \%$ dos idosos incluídos neste trabalho foram vítimas de queda.

Dentre os eventos registrados na presente pesquisa como causadores do agravo à saúde por acidentes e violências nos idosos, a queda ficou em primeiro lugar, com um total de 50 casos, o que representa $81 \%$ dos atendimentos dispensados aos idosos vitimados por acidentes e violências. Em seguida, ficaram os acidentes de transporte com $16 \%$ (10 casos) das ocorrências, e as agressões representando $3 \%$ ( 2 casos) dos atendimentos. Esses resultados são diferentes dos apresentados no Plano de Ação para o Enfrentamento da Violência Contra a Pessoa Idosa, que ao analisar o Sistema de Informações Hospitalares do SUS, em 2004, verificou que das 108.169 internações por violências e acidentes em idosos, 55,38\% correspondiam 
a quedas; $19,1 \%$ a acidentes de trânsito, sobretudo a atropelamentos; 3,0\% a agressões; e 0,8\%, a lesões autoprovocadas (BRASIL, 2005).

Os homens foram acometidos em $56 \%$ ( 35 casos) do total de atendimentos. Com a estratificação desses eventos na população masculina, pode-se identificar que $42 \%$ ( 26 casos) dos atendimentos foram referentes às quedas; $11 \%$ ( 7 casos) por acidentes de transporte; e $3 \%$ ( 2 casos) frutos de agressões. Por outro lado, não foi identificado caso de violência contra a mulher idosa. As ocorrências nesse grupo se concentraram nos eventos relacionados às quedas e acidentes de transporte, que apresentaram respectivamente $39 \%$ ( 24 casos) e $5 \%$ ( 3 casos), totalizando $44 \%$ ( 27 casos) dos atendimentos prestados à pessoa idosa vitimada por acidentes e violências.

Pode-se observar através dos dados encontrados, o quão representativo é o evento relacionado à queda no cotidiano da população idosa. Estudos demonstram que dentre os fatores associados a esses eventos estão a idade avançada, o uso de múltiplos medicamentos, a inadequação dos ambientes domésticos, a capacidade funcional reduzida e as alterações fisiológicas comuns nesse período da vida, além dos eventos relacionados à violência doméstica que são mascarados como queda acidental (NAKAGAWA et al., 2017; COUTINHO; SILVA, 2002; SOUZA et al., 2003; VERAS, 2009; CAVALCANTE, 2012).

Os fatores relacionados acima podem justificar o motivo pelo qual $42 \%$ ( 21 casos) dos atendimentos de queda envolvendo idosos atendidos pelo SAMU 192 no Espírito Santo ocorreram no período noturno. Em uma avaliação de risco para a ocorrência de acidentes no ambiente doméstico envolvendo idosos realizada por Grossi (2007), identificou-se que $50 \%$ dos domicílios apresentavam desníveis em seu interior e $75 \%$ utilizava tapetes que representavam risco de queda. Além disso, somente $50 \%$ dos idosos referiram desfrutar de uma boa iluminação em todos os cômodos.

Em meio aos problemas que envolvem a capacidade funcional está a diminuição da força muscular nas extremidades inferiores, considerado um fator de risco crítico para a ocorrência de quedas. Porém, segundo os achados de Lastayo et al. (2017), através de intervenções terapêuticas por meio de exercícios específicos, essa condição pode se tornar reversível, promovendo a redução das ocorrências de quedas.

Outras estratégias também devem ser pensadas, como já é preconizado pelo Plano de Ação para o Enfrentamento da Violência Contra a Pessoa Idosa, que ressalta a importância do espaço familiar considerando a necessidade na preparação da casa para maior segurança e na formação de cuidadores familiares para os idosos dependentes (BRASIL,2005).

No presente estudo, pudemos identificar através da pesquisa de campo que $18 \%$ ( 9 casos) dos idosos vitimados por queda (50 casos) apresentaram registro de hálito etílico evidente durante o atendimento. A ingestão excessiva de bebida alcoólica é outro fator que representa riscos de queda e, consequentemente, à saúde em qualquer grupo etário. Entretanto, na pessoa idosa o risco de cair após o uso de bebidas etílicas torna-se mais intenso em decorrência da associação das alterações fisiológicas do envelhecimento com o uso abusivo dessas substâncias. Amaro et al. (2008) sugerem que os eventos de queda em idosos, quando agregados ao uso de bebida alcoólica, resultam em lesões mais graves.

O acidente de trânsito é outra causa de morte da população idosa que precisa da atenção das autoridades públicas. Identificamos neste estudo que $16 \%$ (10 casos) dos atendimentos aos idosos vitimados por acidentes e violências foram frutos desses episódios. Esses dados são inferiores ao exposto por Barros et al. (2013) ao analisarem a assistência prestada aos idosos por um serviço de atendimento pré-hospitalar móvel no município de João Pessoa/PB, onde a frequência dos acidentes de trânsito no indivíduo idoso traumatizado foi de $24 \%$, sendo estratificados em atropelamentos ( $15 \%$ dos acidentes de trânsito) e acidentes automobilísticos ( $9 \%$ dos acidentes de trânsito).

Em harmonia com Barros et al. (2013), Freitas et al. (2015) identificam o atropelamento como o acontecimento mais frequente dentre os acidentes de trânsito envolvendo idosos. O presente estudo segue em consonância com os autores supracitados, pois foi identificado que esses eventos foram responsáveis por $60 \%$ (6 casos) dos atendimentos a idosos que sofreram lesões por acidentes de trânsito, divididos igualmente entre os gêneros.

Esses resultados reforçam, mais uma vez, o que já está posto no Plano de Ação para o Enfrentamento da Violência Contra a Pessoa Idosa que registram a necessidade de preparar melhor os dispositivos e sinais 
nas ruas e nas travessias nas cidades; promover campanhas educativas para a população em geral; colocar conteúdos sobre os direitos dos idosos nas escolas de formação de motoristas e mobilizar os empresários do setor e punir os agressores (BRASIL, 2005).

O equilíbrio entre os gêneros não foi verificado neste estudo quando o assunto foi a violência. As vítimas de atos violentos registrados nos boletins de ocorrência do SAMU 192 foram do sexo masculino e os mecanismos de lesão utilizados foram a arma branca e a arma de fogo, sendo que esse último apresentou óbito no local da ocorrência. Não foi identificado nenhum outro tipo de agressão, o que nos conduz à reflexão sobre a existência de casos de violências camuflados dentre os outros tipos de eventos, mantendo-nos assim em consonância com a teoria de Grossi et al. (2007), de que os casos de violências que ocorrem no âmbito domiciliar podem permanecer ocultos e disfarçados como, por exemplo, uma queda.

Por outro lado, o presente estudo está em discordância com os achados do estudo de Grossi et al. (2007), realizado através da análise dos registros do Relatório de Notificação Individual de Acidentes e Violências (RINAV) no município de Guaíba/RS, onde foi identificado que $82 \%$ dos casos de violências contra idosos entre os meses de janeiro e setembro de 2007 foram exercidos contra a mulher idosa, estando assim, bem distante da realidade encontrada nos registros dos atendimentos realizados pelo SAMU 192 do Espírito Santo, que não apresentou nenhum registro de violência contra a mulher idosa, fortalecendo a teoria da ocultação.

Para a realização dos atendimentos às solicitações de socorro para idosos que sofreram algum tipo de violência ou acidente foi enviada a equipe da Unidade de Suporte Básico (USB) em 97\% (60 casos) dos atendimentos e em 3\% (2 casos) o recurso julgado necessário foi a Unidade de Suporte Avançado (USA). No estudo de Barros et al. (2013) os resultados foram equivalentes, sendo $94 \%$ dos atendimentos prestados a idosos vitimados por acidentes e violências realizados pela USA e apenas $6 \%$ pela USA.

Após a realização da avaliação e intervenções possíveis no local do evento, a equipe de intervenção do serviço de atendimento pré-hospitalar, quando necessário, encaminha a vítima para um serviço hospitalar sob orientação do médico regulador. Identificamos neste estudo que $92 \%$ ( 57 casos) dos pacientes atendidos por violências e acidentes foram encaminhados para uma instituição de saúde, $3 \%$ ( 2 casos) foram liberados no local, outros $3 \%$ ( 2 casos) recusaram atendimento e $2 \%$ (1 caso) foram a óbito no local do evento.

Os resultados apresentados tornam evidente que um dos acessos do idosos vítima de violência ao sistema de saúde se faz pelo SAMU. Esse fato reforça a necessidade de se inserir nas rotinas dos serviços de assistência pré-hospitalar móvel, como defendido por Minayo et al. (2018) normas técnicas relativas ao diagnóstico dos traumas e lesões. Tendo em vista que a equipe de saúde tem papel importante na notificação de mortes e agravos em decorrência da violência.

Ao identificar os tipos de agravos à saúde da população idosa relacionados aos acidentes e violências, e os profissionais que atuam diretamente na assistência durante o período agudo da emergência, estamos em consonância com Barros et al. (2013), ao afirmamos que por meio desses dados pode-se acompanhar o desenvolvimento desses eventos sobre a população idosa, permitindo a adoção de estratégias de prevenção e controle, além de auxiliar no preparo dos profissionais para identificar casos de acidentes e de violências e lidar com mais especificidade diante desses episódios.

\section{Considerações finais}

A condição física e mental que as pessoas chegam atualmente na terceira e quarta idade são muito melhores às observadas no passado, proporcionando uma vida mais ativa e independente. Essa condição se dá pelo avanço tecnológico e científico, associado a medidas políticas como, por exemplo, o saneamento básico e os programas de prevenção em saúde.

Entretanto, por décadas os casos de violências e acidentes vêm configurando um problema social de grande relevância e mantêm um movimento de ascensão contínuo. Associada a essa crescente incidência, vem ocorrendo uma transição demográfica, com o aumento da proporção de idosos e a redução da natalidade. 
É verdade que observamos uma maior frequência dos casos de violências e de acidentes nas pessoas compreendidas nas faixas etárias mais jovens, onde esses eventos representam a principal causa de morte. Entretanto, nos últimos anos, identificamos uma prevalência importante nos idosos, em especial nos indivíduos mais longínquos.

Apesar de apresentarem uma condição mais favorável que no passado, as alterações fisiológicas do envelhecimento desfavorecem um deslocamento seguro, seja no ambiente domiciliar ou mesmo nas vias públicas, além de uma maior fragilidade para a autoproteção, em consequência da redução da força e agilidade, exprimindo uma condição de maior vulnerabilidade em relação aos indivíduos mais jovens.

Além de mais vulneráveis, a população idosa apresenta um potencial de recuperação inferior aos indivíduos mais jovens, culminando em uma permanência maior durante as internações hospitalares quando vitimados por acidentes e violências, sendo expostos a riscos de complicações, como infecções hospitalares. Por vezes, essas lesões resultam em uma condição de invalidez do idoso, como é o caso das fraturas do colo de fêmur.

$\mathrm{O}$ atendimento precoce e adequado ao idoso vitimado por acidentes e violências é extremamente importante para uma melhor recuperação. A Região Metropolitana do Espírito Santo dispõe do SAMU 192 para iniciar o cuidado ainda no local do evento, que também é uma das formas de acesso ao sistema de saúde dos idosos vítimas de acidentes e violências.

Dentre os atendimentos realizados por esse serviço, identificamos uma frequência elevada das quedas em relação aos outros tipos de eventos na população idosa. A fonte de dados utilizada não nos permitiu identificar a causa que desencadeou o evento, mas através dos levantamentos realizados na literatura acredita-se que está relacionado ao ambiente domiciliar inadequado, uso de medicamentos, alterações fisiológicas comuns ao período da vida, como a diminuição da acuidade visual, redução da força e do equilíbrio, entretanto, como dito anteriormente, não se pode descartar a possibilidade de violência doméstica nesses episódios.

A instituição de políticas públicas com foco na orientação, prevenção e promoção de ambientes saudáveis, atividades físicas específicas para a idade e atividades para o desenvolvimento da acuidade mental, de forma acessível ao idoso, terá um impacto positivo sobre a redução das quedas no indi víduo idoso.

Não identificamos nenhum registro de violência contra a mulher, no entanto, não podemos afirmar que isso é uma realidade na região estudada, visto que os autores estudados se referem a uma ocultação de casos de violências sobre os idosos e a prevalência de violência contra a mulher em outros estudos afins demonstraram altas incidências.

Ressaltamos ainda que, o treinamento dos profissionais do SAMU 192 com ênfase na assistência préhospitalar ao paciente idoso é pertinente pois, um atendimento qualificado além de implicar em redução de custos, pode melhorar o prognóstico para a vítima. Ademais, um profissional bem instruído teria um olhar mais acurado para identificar sinais de abuso e violência, tanto pelas características das lesões encontradas nas vítimas, quanto nos indícios deixados no ambiente.

\section{Referências}

ALBUQUERQUE, V. S. Violência sob o olhar e o agir de quem socorre: representações dos profissionais do atendimento pré-hospitalar de urgência e emergência. 2010. 195 f. Tese (Doutorado) - Escola Nacional de Saúde Pública Sergio Arouca. Rio de Janeiro, 2010. https://doi.org/10.5327/z1679443520180307

AMARO, F. A. B. et al. Análise da incidência de quedas e fraturas nos idosos etilistas. Revista Terapia Manual, Goiás, v, 6. n. 27, p. 254-258, 2008.

BARROS, M. A. A. et al. Características dos agravos e da assistência prestada aos idosos em um serviço pré-hospitalar móvel. Revista de Enfermagem UERJ, Rio de Janeiro. v. 21, n. 1, p. 569-574, 2013. https://doi.org/10.24276/

rrecien2358-3088.2018.8.23.12-20 
BERNADO, M. H. de J; ASSIS, M. Saúde do idoso e a integralidade da atenção. In: DUARTE, M. J. de O. et al. Política de saúde hoje. São Paulo: Papel Social, 2014. p. 317-333. https://doi.org/10.11606/t.7.2012.tde-08012013-110534

BRASIL. Presidência da República. Subsecretaria de Direitos Humanos. Plano de Ação para o Enfrentamento da Violência Contra a Pessoa Idosa. Brasília, DF: Subsecretaria de Direitos Humanos, 2005. https://doi.org/10.1590/141381232014198.06322014

BRASIL. Ministério da Saúde. DATASUS/SIM: estatísticas vitais: mortalidade - 1979-1995, pela CID9. Disponível em: http://tabnet.datasus.gov.br/cgi/deftohtm.exe? sim/cnv/obt09uf.def. Acesso em: 24 jan. 2018 a.

BRASIL. Ministério da Saúde. DATASUS/SIM: estatísticas vitais: mortalidade - 1996-2015, pela CID10. Disponível em: http://tabnet.datasus.gov.br/cgi/ deftohtm.exe?sim/cnv/ obt10uf.def. Acesso em: 24 jan. 2018 b.

BRASIL. Ministério da Saúde. DATASUS/SIM: População residente por Unidade da Federação segundo Município. Disponível em: http://tabnet.datasus.gov.br/cgi/tabcgi.exe?novapop/cnv/popbr.def. Acesso em: 18 mar. $2018 c$.

CAVALCANTE, A. L. P.; AGUIAR, J. B.; GURGEL, L. A. Fatores associados a quedas em idosos residentes em um bairro de Fortaleza, Ceará. Revista Brasileira de Geriatria \& Gerontologia, Rio de Janeiro, v. 15, n. 1, p. 137-46, 2012. https://doi. org/10.1590/s1809-98232012000100015

COUTINHO, E. S. F.; SILVA, S. D. Uso de medicamentos como fator de risco para fratura grave decorrente de queda em idosos. Cadernos de Saúde Pública. Rio de Janeiro, v.18, n. 5, p. 1359-66, 2002. https://doi.org/10.1590/s0102$311 \times 2002000500029$

DIEL, M; BARBIANI, R. Violência familiar contra a pessoa idosa: expressões do fenômeno e perspectiva para o seu enfrentamento. Textos \& Contextos, Porto Alegre. v. 17, n. 2, p. 379-392, 2018. https://doi.org/10.15448/16779509.2018.2.27484

ESPÍRITO SANTO. Portaria no 122-R, de 04 de julho de 2012. Institui a Política de Atenção à Saúde da Pessoa Idosa no âmbito do Sistema Único de Saúde do Espírito Santo. Espírito Santo, ES: SESA, 2012. https://doi. org/10.17655/9788567211534

ESPÍRITO SANTO. Secretaria de Estado da Saúde. Indicadores de saúde, 2014.

ESPÍRITO SANTO. Secretaria de Estado da Saúde. SESA inicia a discussão sobre a reorganização da rede de atenção à saúde do idoso no Espírito Santo. Texto disponibilizado em 12 nov. 2018. In: Portal da Secretaria de Estado da Saúde do Espírito Santo. [S. I.: s. n.], 2018. Disponível em: https://saude.es.gov.br/Not\%C3\%ADcia/sesa-inicia-discussaosobre-reorganizacao-da-rede-de-atencao-a-saude-do-idoso-no-espirito-santo. Acesso em: 07 abr 2019. https://doi. org/10.17655/9788567211534

FREITAS, M. G. et al. Elderly patients attended in emergency health services in Brazil: a study for victims of falls and traffic accidents. Ciência \& Saúde Coletiva, Rio de Janeiro, v. 20, n. 3, p. 701-712, 2015. https://doi.org/10.1590/141381232015203.19582014

GARCIA FILHO, C.; SAMPAIO, J. J. C. Interfaces entre a história da violência e a constituição do território do Ceará: um esforço de síntese e periodização. Saúde Social, São Paulo, v. 23, n. 4, p. 1209-21, 2014. https://doi.org/10.1590/s010412902014000400008

GENTILLI, R. M. L. Transformações societárias recentes e as raízes da violência atual. In: GENTILLI, R. M. L.; COELHO, M. C. R. Investigações sobre violência e sociabilidade: desafios transdisciplinares. São Paulo: Veras, 2015. p. $19-40$

GROSSI, P. K. et al. Rompendo o silêncio: violências e acidentes com idosos no município de Guaíba/RS. Revista do Programa de pós-graduação em Política Social, v. 1, n. 1, Brasília, 2007.

HEYDARI-KHAYAT, N. et al. Correlation of Revised Trauma Score with mortality rate of traumatic pacients within the first 24 hours of hospitalization. Zahedan Journal of Research in Medical Sciences; Isfahan, v. 16, n. 11, p. 33-6, Nov. 2014.

INSTITUTO BRASILEIRO DE GEOGRAFIA E ESTATÍSTICA. Pesquisa nacional por amostragem de domicílios: Síntese de indicadores 2015. Rio de Janeiro: IBGE, 2016. https://doi.org/10.17143/ciaed/xxiilciaed.2017.00322 
LASTAYO P; et al. Eccentric versus traditional resistance exercise for older adult fallers in the community: a randomized trial within a multi-component fall reduction program. BMC Geriatrics, [S. I.], 2017. Disponível em: https://www.ncbi.nlm. nih.gov/pmc/articles/PMC5513167/. Acesso em 16 de junho de 2018. https://doi.org/10.1186/s12877-017-0539-8

MELLO, A. L. S. F.; MOYSÉS, S. J. Análise diagnóstica do atendimento pré-hospitalar para acidentes e violências contra idosos em Curitiba (PR, Brasil). Ciência \& Saúde Coletiva, Rio de Janeiro, v. 15, n. 6, p. 2709-2718, 2010. https://doi. org/10.1590/s1413-81232010000600009

MINAYO, M. C. S.; SOUZA, E. R. É possível prevenir a violência? Reflexões a partir do campo da saúde pública. Ciência \& Saúde Coletiva, Rio de Janeiro, v. 4, n. 1, p. 7-32, 1999. https://doi.org/10.1590/s1413-81231999000100002

MINAYO, M. C. S. The inclusion of violence in the health agenda: historical trajectory. Ciências \& Saúde Coletiva, Rio de Janeiro, v. 11 (Sup), p. 1259-1267, 2007.

MINAYO, M. C. S. Seis características das mortes violentas no Brasil. Revista Brasileira de Estudos de População, São Paulo, v. 26, n. 1, p. 135-140, 2009. https://doi.org/10.1590/s0102-30982009000100010

MINAYO, M. C. S. et al. Institucionalização do tema da violência no SUS: avanços e desafios. Ciências \& Saúde Coletiva, Rio de Janeiro, v. 23, n. 6, p. 2007-2016, 2018. https://doi.org/10.1590/1413-81232018236.04962018

NAKAGAWA H.B. et al. Postural balance and functional independence of elderly people according to gender and age: cross-sectional study. São Paulo Med Journal, São Paulo, v. 135, n. 3, p. 260-265, 2017. https://doi.org/10.1590/15163180.2016 .0325280217

PAIVA, S. de O. C. O direito à saúde do(a) velho(a) trabalhador(a) escrito no diário da proteção social brasileira: resultado das lutas sociais da classe trabalhadora. In: PAIVA, S. de O. C. Envelhecimento, saúde e trabalho no tempo do capital São Paulo: Cortez, 2014. p. 161-218. https://doi.org/10.11606/t.6.2008.tde-10042008-115233

REIS, C. S. et al. Envelhecimento populacional e gastos com internação do SUS. Revista Brasileira de Estudos de População, Rio de Janeiro, v. 33, n. 3, p. 591-612, 2016. https://doi.org/10.20947/s0102-30982016c0007

SILVEIRA R. E. et al. Gastos relacionados a hospitalizações de idosos no Brasil. Einstein, São Paulo, v. 11, n. 4, p. 514-520, 2013. https://doi.org/10.1590/s1679-45082013000400019

SMARZARO, D. C. A informação sobre mortes por causas externas: estudo do preenchimento da causa básica de óbito em um serviço de medicina legal no Espírito Santo 2000-2002. 2005. 90f. Dissertação (Mestrado) - Escola Nacional de Saúde Pública Sergio Arouca, Rio de Janeiro, 2005. https://doi.org/10.5123/s1679-49742012000300006

SOARES, A. M. Violência como fenômeno intrínseco à cultura política brasileira. Sinais, Vitória-ES, n. 18, p. 92-108, 2015.

SOUZA, K. T. S. et al. Idosos vítimas de acidentes de trânsito: aspectos epidemiológicos e impacto na sua vida cotidiana. Acta Scientiarum Health Sciences, Maringá, v. 25, n. 1, p. 19-25, 2003. https://doi.org/10.4025/actascihealthsci.v25i1.2247

TEIXEIRA, S.M.O. et al. Da velhice estigmatizada à dignidade na existência madura: novas perspectivas do envelhecer na contemporaneidade. Estudos \& Pesquisas em Psicologia, Rio de Janeiro, v. 16, n. 2, p. 469-487, 2016. https://doi. org/10.12957/epp.2016.29179

VERAS, R. Envelhecimento populacional contemporâneo: demandas, desafios e inovações. Revista de Saúde Pública, Rio de Janeiro, v. 43, n. 3, p. 548-554, 2009. https://doi.org/10.1590/s0034-89102009000300020

Recebido em: $21 / 6 / 2018$

Aprovado em: 12/4/2019.

Publicado em: 10/10/2019.

Correspondência para:

Leonardo França Vieira

Escola Superior de Ciências da Santa Casa de Misericórdia de Vitória

Av. Nossa Senhora da Penha, 2190 - Santa Luzia

29045-402 Vitoria, ES - Brasil 


\section{Autores:}

LEONARDO FRANÇA Vieira

Mestre em Políticas Públicas e Desenvolvimento Local pela Escola Superior de Ciências da Santa Casa de Misericórdia de Vitória (EMESCAM), Vitória, ES, Brasil. Professor dos cursos de enfermagem e medicina da Escola Superior de Ciências da Santa Casa de Misericórdia de Vitória, Vitória, ES, Brasil.

Orcid: https://orcid.org/0000-0002-4414-9267

E-mail: leonardof.vieira@emescam.br

\section{CAIO DUARTE NETO}

Mestre em Políticas Públicas e Desenvolvimento Local pela Escola Superior de Ciências da Santa Casa de Misericórdia de Vitória (EMESCAM), Vitória, ES, Brasil. Professor da Escola Superior de Ciências da Santa Casa de Misericórdia de Vitória, Vitória, ES, Brasil.

Orcid: https://orcid.org/0000-0002-9927-1374

E-mail: caioduarteneto@gmail.com

\section{LUCIANA CARRUPt MACHADO SOgame}

Doutora em Ciências pela Universidade Federal de São Paulo (UNIFESP), São Paulo, SP, Brasil. Professora da Escola Superior de Ciências da Santa Casa de Misericórdia de Vitória, Vitória, ES, Brasil.

Orcid: https://orcid.org/0000-0001-6913-5497

E-mail: luciana.sogame@emescam.br 